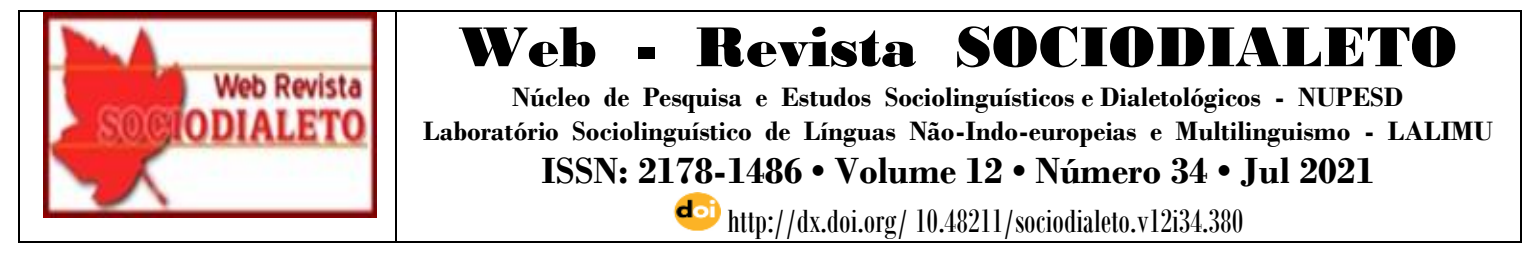

\title{
REFLEXÕES SOBRE A PRÁTICA DOCENTE NO ENSINO SUPERIOR NO ENSINO DE LIBRAS
}

REFLECTIONS ON TEACHING PRACIICE IN HIGHER EDUCATION IN THE TEACHING OF LIBRAS

\author{
Claudiane Santos Araújo (UFMA) ${ }^{1}$ \\ claudiane.araujo@ufma.br
}

\begin{abstract}
RESUMO: O presente estudo possibilita a reflexão sobre as experiências docentes no ensino da Língua Brasileira de Sinais (LIBRAS) como segunda língua em instituições de ensino superior maranhenses. A partir da vivência como professora de Libras no ensino superior foi possível perceber a necessidade da ressignificação da prática docente no ensino desta língua para que se garanta o sucesso do aluno surdo. Nesse sentido, os objetivos desta pesquisa são analisar a prática docente dos professores de Libras no ensino superior, perceber de que forma acontece a prática docente no aprendizado da língua de sinais e refletir sobre a práxis educativa no ensino superior no que tange ao ensino da língua de sinais e seu aprendizado como segunda língua. Dessa forma, o arcabouço teórico-metodológico que sustentam esta pesquisa é a pesquisa bibliográfica, à luz dos estudos de Gil (2008), Lakatos \& Marconi (2012) a partir da revisão de literatura sobre o processo histórico da educação de surdos, pois é uma categoria histórica. As reflexões teóricas estão de acordo com os posicionamentos de Quadros (1997;2006), Gesser (2009;2012), Santos (2015), Strobel (2009), dentre outros.
\end{abstract}

PALAVRAS-CHAVE: Docência; Formação; Surdos

\begin{abstract}
This study allows reflection on teaching experiences in teaching the Brazilian Sign Language (LIBRAS) as a second language in institutions of higher education in Maranhão. From the experience as a teacher of Libras in higher education, it was possible to perceive the need to redefine the teaching practice in teaching this language in order to guarantee the success of the deaf student. In this sense, the objectives of this research are to analyze the teaching practice of Libras teachers in higher education, to understand how the teaching practice happens in the learning of sign language and to reflect on the educational praxis in higher education with regard to language teaching. of signs and their learning as a second language. Thus, the theoretical and methodological framework that support this research is bibliographic research, in the light of the studies by Gil (2008), Lakatos \& Marconi (2012) from the literature review on the historical process of deaf education, as it is a historical category. Theoretical reflections are in line with the positions of Quadros (1997; 2006), Gesser (2009; 2012), Santos (2015), Strobel (2009), among others.
\end{abstract}

KEYWORDS: Teaching; Training; Deaf

\section{Introdução}

Os desafios impostos pela educação que se pauta pelos modelos inclusivos se constituem como complexos, contemporâneos traduzindo-se, em grande parte, por

\footnotetext{
${ }^{1}$ Professora do Departamento de Letras da Universidade Federal do Maranhão (UFMA).
} 


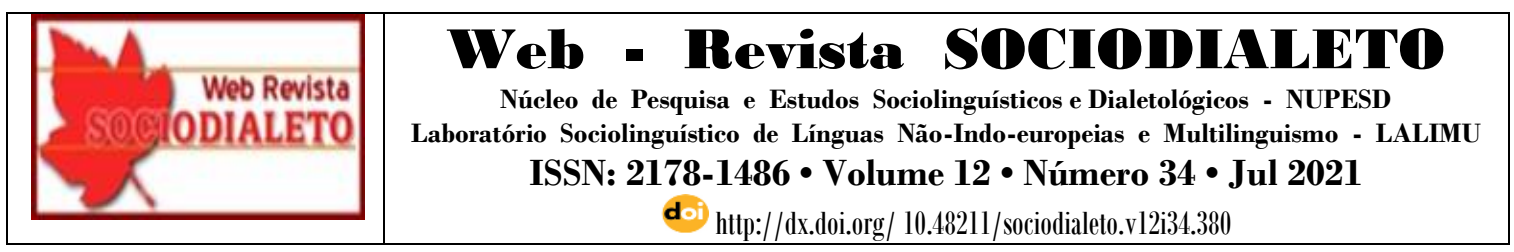

dificuldades de edificação de uma prática que efetivamente contemple em suas ações, o surdo ou pessoas que tem necessidades educacionais especiais.

O professor de LIBRAS, imerso no novo cenário educativo que se deseja construir na ótica das práticas inclusivas, tem pela frente grandes desafios de fazer acontecer, de fato práxis que consigam agregar em seus bojos todos e todas as pessoas numa escola de aprendizagem.

E neste contexto ímpar, de escola onde a aprendizagem se converte em meta para todos, focalizamos a presença do surdo, como sujeito que demanda, da escola, uma nova tomada de posição: a sala de aula deve ser consolidada em moldes bilíngues, onde coexistam a Língua Portuguesa e a Libras, como canais de comunicação favorecedores das experiências de ensino aprendizagens para todos os cidadãos.

A educação de surdos em nosso país tem ultrapassado inúmeras barreiras e conquistado muitos espaços, que até aproximadamente uns 100 anos atrás não se poderia pensar, colocando a comunidade surda e seus sujeitos principais em um patamar visual propício para se discutir sobre os mais diversos temas à que eles estão relacionados.

A vinda de Ernest Huet, a convite do então imperador Dom Pedro II em 1855 para fundar uma escola para surdos, juntamente com essa fundação ${ }^{2}$ configuram ponto de partida para que hoje possamos fazer um recorte histórico da Libras no BRASIL.

Atualmente a LIBRAS já se faz presente em quase todos os espaços e é quase difícil encontrar alguém que não saiba do que ela se trata mesmo que não tenha conhecimentos básicos, bem como pessoas que tenham interesse na aprendizagem desta língua ou mesmo quem já fez algum curso, oficina de LIBRAS e que não tendo praticado, esqueceu. Muitos já pisaram na terra, até então estrangeira, da cultura e do povo surdo.

\footnotetext{
${ }^{2}$ Em 1857 foi fundado no Rio de Janeiro o Imperial Instituto de Surdos-Mudos atualmente chamado de Instituto Nacional de Educação de Surdos - INES. Atualmente algumas pesquisas indicam certas discordâncias sobre essa vertente da história. Em algumas fontes é possível identificar que na realidade, a vinda de Huet para o Brasil, bem como a ida de Laurent Clerc para os Estados Unidos estava mais ligado à um projeto do Instituto de Paris que objetivava abrir novas escolas de educação de surdos em outros países, garantindo assim tanto a educação de surdos quanto a difusão da língua de sinais.
} 


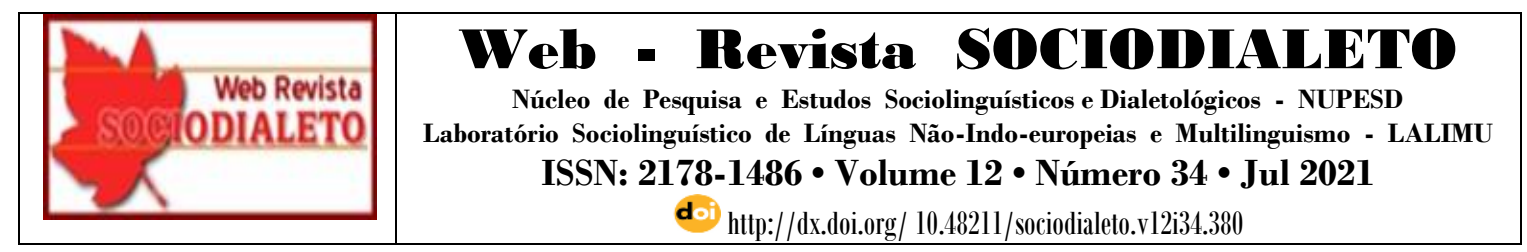

$\mathrm{O}$ interesse nesta pesquisa surgiu do fato de se pensar de que forma acontecem a experiências docentes no nível superior de ensino, uma vez que ao inserir o ensino de LIBRAS nos cursos de graduação permitiu que houvesse uma abertura maior para o conhecimento sobre a forma como o surdo se comunica.

Portanto, os objetivos desta pesquisa são analisar a prática docente dos professores de Libras, perceber de que forma acontece a prática docente no aprendizado da língua de sinais e refletir sobre a práxis $^{3}$ educativa no ensino superior no que tange ao ensino da língua de sinais e seu aprendizado como segunda língua.

Nesse viés, recorre-se ao método de pesquisa bibliográfica ${ }^{4}$ em que se busca saber e dialogar com as produções teóricas relacionadas ao tema, junta-se à isso, na parte final do trabalho o relato de experiência de professores surdos que atuam em instituições de ensino superior maranhenses. Busca-se fazer uma discussão com autores ${ }^{5}$ da temática, bem como inserimos a legislação. A Lei 10.436 de abril de 2002 que reconhece e oficializa a Libras bem como o Decreto 5.626 que a regulamentam são fundamentais para embasar nosso estudo. Outrossim, temos as reflexões sobre as experiências docentes de professores surdos e ouvintes que, inseridos ensino superior, exercem sua prática pedagógica no ensino de Libras como segunda língua nos cursos de graduação de determinadas instituições de ensino superior ludovicenses. Ademais, o estudo tem relevância para a educação na medida que instiga a discussão e reflexão sobre a educação de surdos e estimula a ressignificação da prática docente para aprendizagem desses sujeitos no ensino superior.

\footnotetext{
${ }^{3}$ A práxis educativa na perspectiva freiriana, por exemplo, se constitui na reflexão e ação dos homens sobre o mundo para transformá-lo. $O$ embate dialético entre ação-reflexão presente neste método favorece a uma mudança da consciência humana da estrutura social e a uma aproximação crítica, reflexiva da realidade estudada. (FREIRE, 2009)

${ }^{4}$ MARCONI, Maria de Andrade; LAKATOS, Eva Maria. Metodologia do trabalho científico. 7. ed. São Paulo: Atlas, 2012

${ }^{5}$ QUADROS (1997;2006), GESSER (2009;2012), SANTOS (2015), STROBEL (2007;2009) entre outros autores
} 


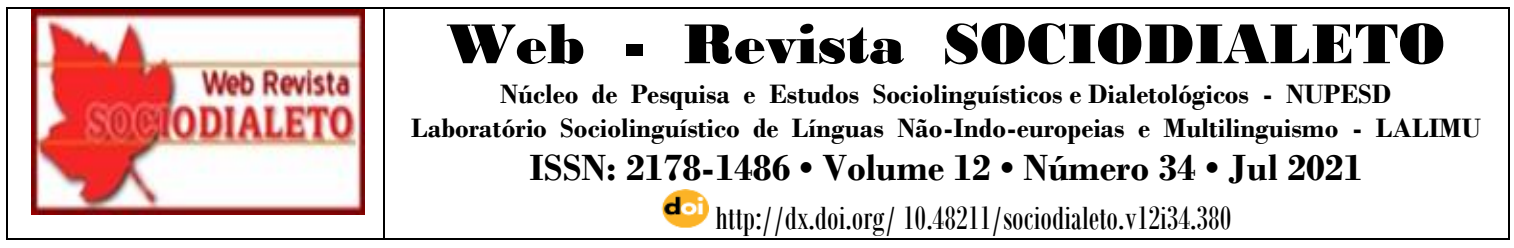

\section{O ensino para surdos à luz do bilinguismo: perspectivas e desdobramentos teóricos}

O bilinguismo que pode parecer ser contemporâneo, mas é bem mais antiga que o Oralismo $^{6}$, se considerarmos por exemplo, que o uso dos sinais pelos surdos é um fato mais do que natural, compreende o sujeito como possuidor de modo de ver, ouvir e entender o mundo de uma maneira diferente dos demais grupos sociais.

Do ponto de vista educacional, o bilinguismo entende que a educação dos surdos deva ser feita em língua de sinais, sua língua natural, materna que será caracterizada como sua primeira língua (L1). Então prossegue-se com o ensino da língua oral apenas em sua modalidade escrita que será sua segunda língua (L2). Diferente das anteriores, aqui foi possível perceber um sucesso grandioso no processo de ensino-aprendizagem dos surdos. Fato perceptível atualmente, uma vez que podemos ver a presença deles nos mais diferentes espaços de atuação, sendo autores de sua própria história.

Se a língua de sinais é uma língua natural adquirida de forma espontânea pela pessoa surda em contato com as pessoas que usam essa língua e se a língua oral é adquirida de forma sistematizada, então as pessoas surdas têm o direito de ser ensinadas na língua de sinais. A proposta bilíngue busca captar esse direito. (QUADROS, 1997, p. 26)

Os caminhos da educação bilíngue ainda estão sendo trilhados. E principalmente a reflexão sobre essa proposta segue avançando e apesar dos desafios, ela é hoje a que mais se destaca no que diz respeito à garantia dos direitos do povo surdo no uso de sua língua e no conhecimento de sua cultura, dando possibilidade também para conhecer sobre o mundo do ouvinte.

A partir daqui é importante destacar que esses avanços pelos quais a língua de sinais passou, configurou cenários importantes como a aprovação da Lei 10.436/2002 que reconheceu a LIBRAS como língua oficial da comunidade surda e do país, bem como o

\footnotetext{
${ }^{6}$ Oralismo no sentido clínico-terapêutico para tratar a falta de audição dos surdos e fazê- los falar trazendo como consequência a proibição da língua de sinais e a tentativa de desintegração do Ser Surdo. (QUADROS, 2006)
} 


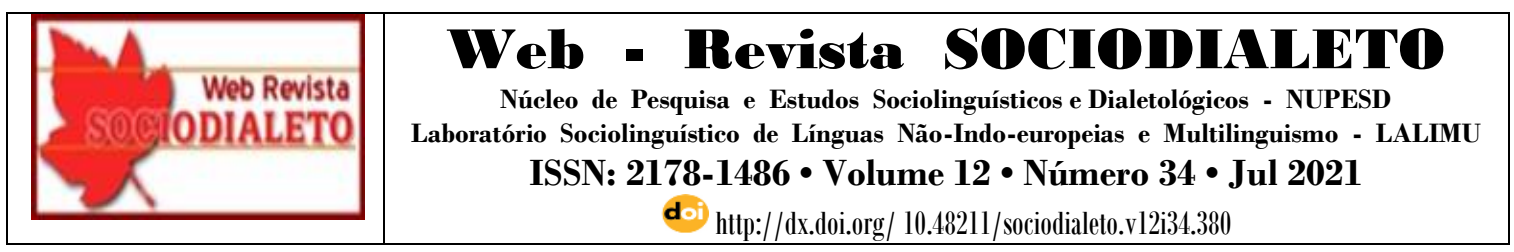

Decreto 5.626/2005 que a regulamentou e estabeleceu orientações sobre o uso e difusão da LIBRAS não só pela comunidade surda como pelas demais pessoas além disso garantiu a conquista pela educação bilíngue.

Sobre a oficialização da LIBRAS temos a seguinte definição

Art. $1^{\circ}$ É reconhecida como meio legal de comunicação e expressão a Língua Brasileira de Sinais - Libras e outros recursos de expressão a ela associados.

Parágrafo único. Entende-se como Língua Brasileira de Sinais - Libras a forma de comunicação e expressão, em que o sistema lingüístico de natureza visual-motora, com estrutura gramatical própria, constituem um sistema lingüístico de transmissão de idéias e fatos, oriundos de comunidades de pessoas surdas do Brasil. (BRASIL, 2002)

E sobre sua regulamentação temos vários aspectos que podem ser discutidos, mas aqui cabe mencionar apenas que a LIBRAS se tornou disciplina obrigatória nos cursos de formação de professores (licenciaturas) e fonoaudiologia. Isso significa que a possibilidade de surdos e ouvintes terem contato com esta língua se tornou cada vez mais crescente. Obviamente que não estamos dizendo que tudo isso possibilitou de forma fácil a inserção de surdos nos espaços. Muitas lutas foram, são e serão travadas ainda para se atingir o patamar desejado.

[...] Em primeiro lugar, devemos ponderar que o decreto por si só não elimina o sentimento de culpa e os dramas vividos no seio familiar, nem tampouco os fracassos educacionais e insucessos na escolarização do surdo. [...] Ouço as pessoas dizerem, entusiasmada e eufóricas, "com o decreto tudo vai mudar...". Contudo, sabemos que apenas o registro legal não basta para garantir mudanças e eliminar preconceitos. (GESSER, 2009, p.79)

Assim, em acordo com o exposto, anos após a oficialização da LIBRAS é possível perceber as lutas, reconhecer os desafios e vislumbrar as conquistas. Daqui pra frente nos deteremos em uma delas, que é a garantia de que os cursos de nível superior tenham 


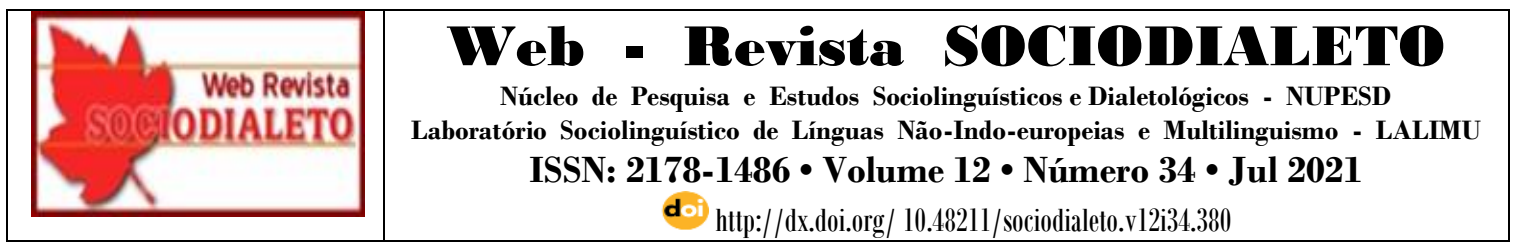

Língua Brasileira de Sinais em seus currículos. Aqui daremos ênfase na prática pedagógica e didática dos professores para o ensino de LIBRAS desse nível. Dessa forma, a seguir, temos aporte teórico sobre o ensino desta língua como segunda língua para ouvintes.

\section{Percursos para se pensar em práticas pedagógicas educacionais bilíngues na perspectiva do ensino superior}

Pedagogicamente, pensar na educação que contemple os surdos, é pensar na ressignificação de processos didáticos e metodológicos, é compreender que há singularidades que precisam ser respeitadas, há portanto, um papel fundamental da formação do professor neste processo de aprendizagem, seja na educação básica, seja no ensino superior.

Na proposta bilíngue os surdos aprendem a língua de sinais como sua primeira língua (L1) e aprendem o português na modalidade escrita (L2) os ouvintes percorrem o caminho inverso, ou seja, aprendem a língua portuguesa como sua primeira língua (L1) e podem aprender como segunda língua (L2) a língua de sinais.

Desta maneira, muitos autores compreendem que neste caso, aprender uma segunda língua corresponde ao aprendizado de uma língua estrangeira. No que diz respeito à esta discussão, temos duas modalidades linguísticas diferentes disponíveis para serem conhecidas, estudadas e utilizadas. Para tanto, é preciso ter contato com essa nova língua que até então é pura e verdadeiramente estrangeira.

Entrar em uma terra estrangeira nunca é fácil. O primeiro passo deve ser o de aprender a língua e a cultura das pessoas que vivem lá. Para os estudantes que desejam visitar o mundo das pessoas Surdas, as aulas de ASL são a porta - aprender a ver é a chave. (WILCOX; WILCOX, 2005, p. 17) 


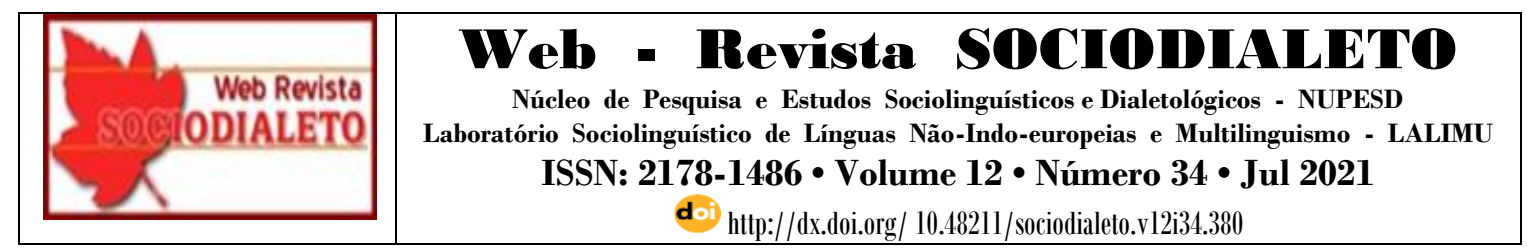

Embora os autores se refiram ao contexto vivido pelos interessados em aprender a Língua Americana de Sinais (ASL) ${ }^{7}$ o mesmo podemos afirmar sobre aspectos gerais de aprendizados das línguas, quer sejam elas orais, quer sejam de sinais. Por conseguinte, também podemos afirmar sobre a aprendizagem da LIBRAS.

É por esse motivo que em algumas teorias existe a defesa de a aprendizagem de primeira e de segunda língua acontecem de forma semelhante, por conta dessa imersão na cultura, por conseguinte dos modos de vida desse grupo linguístico diferente daquele que você já conhece e domina. Assim essa semelhança de aprendizagem está no fato de que a busca por uma comunicação da forma mais natural possível é essencial. (MARTINEZ, 2009).

O interesse na aquisição de segunda língua pode ter inúmeras justificativas, e não queremos aqui discutir sobre este aspecto, no entanto, compreendemos as necessidades anteriormente citadas, mas partimos para a compreensão dessa aquisição linguística a partir de um marco legal regulatório que determinou a presença da língua de sinais nos espaços de aprendizagem e iniciou assim as bases para o ensino da língua brasileira de sinais.

A existência de cursos de qualificação profissional em LIBRAS ou de tradução interpretação em LIBRAS, bem como os cursos de graduação de licenciatura e bacharelado em Letras/LIBRAS ou de tradução e interpretação nos levam a compreender como ocorre essa prática pedagógica no ensino superior. Neste caso, até mesmo as disciplinas nos demais cursos de licenciatura que são obrigatórias e nos bacharelados como optativos nos permitem lançar o olhar sobre essa questão. Aqui cabe destacar acerca disto conforme consta no decreto 5.626 de 2005. Quando traz em seu capítulo II sobre a inclusão da Libras como disciplina.

Art. 3o A Libras deve ser inserida como disciplina curricular obrigatória nos cursos de formação de professores para o exercício do magistério, em nível médio e superior, e nos cursos de Fonoaudiologia, de instituições de ensino, públicas e privadas, do sistema federal de

\footnotetext{
${ }^{7}$ American Sign Language - ASL.
} 


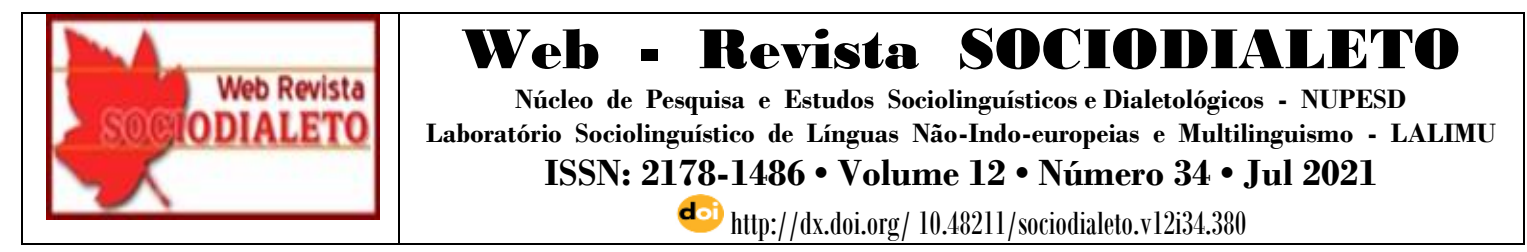

ensino e dos sistemas de ensino dos Estados, do Distrito Federal e dos Municípios.

$\S \mathbf{1}^{\mathbf{0}}$ Todos os cursos de licenciatura, nas diferentes áreas do conhecimento, o curso normal de nível médio, o curso normal superior, o curso de Pedagogia e o curso de Educação Especial são considerados cursos de formação de professores e profissionais da educação para o exercício do magistério.

$\S \mathbf{2}^{\mathbf{0}}$ A Libras constituir-se-á em disciplina curricular optativa nos demais cursos de educação superior e na educação profissional, a partir de um ano da publicação deste Decreto. (BRASIL, 2005)

A presença desse componente curricular nos cursos superiores de graduação possibilita importantes discussões. Qual o sentido do ensino de LIBRAS nos cursos de graduação? Que tipo de conteúdo pode ser trabalhado? Qual foco pode ser abordado? É possível ser fluente a partir do estudo desse componente? Entre outras questões fazem parte daquilo que pode ser vivenciado constantemente nestes espaços. Sobre esta discussão Santos (2015), apregoa:

É por isso que o componente curricular Libras e as discussões a ela relacionadas tornam-se importantes, pois possibilitam aos profissionais em curso um conhecimento acerca das especificidades dos povos surdos e, principalmente, possibilitam destituir a invisibilidade que lhes foi imposta por um século, ao calar essas pessoas, ou seja, "silenciar suas mãos". Talvez esse seja um dos sentidos da sua existência! (SANTOS, 2015, p. 85)

Como o autor aponta, a invisibilidade da língua de sinais aconteceu durante séculos e sua presença na contemporaneidade nos cursos de formações de professores, tornou-se uma conquista na educação de surdos.

Com a crescente demanda nas instituições de ensino superior, o aumento do número de ouvintes em contato com a língua de sinais aumentou consideravelmente e de forma bastante diversificada. Os desafios para os professores giram em torno desse aspecto, pois como fazer para produzir uma aprendizagem significativa diante de um 


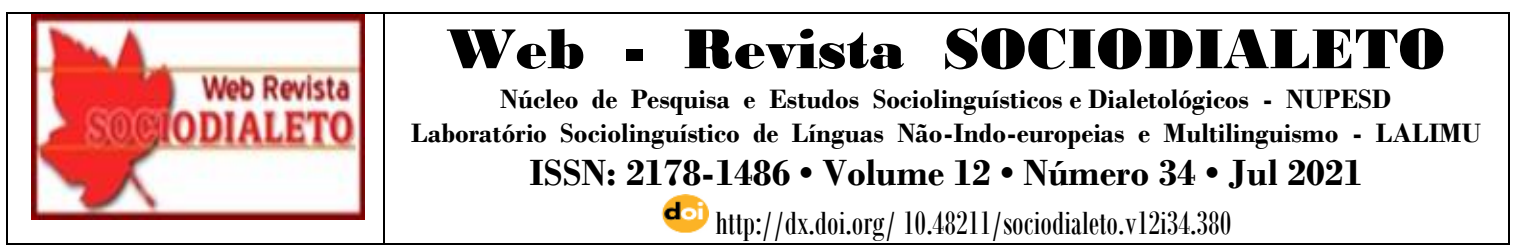

público tão diverso? Que estratégias tomar e que rumos seguir? Quais métodos, procedimentos escolher para atender a peculiaridade de cada aluno?

É certo que isso requer uma ação bastante reflexiva, pois os professores precisam ser capazes de alcançar os alunos que possuem interesses variados. Para tanto, Gesser (2012, p.47) entende que o professor precisa estar sensível à essa variedade de interesses e motivações, pois a partir dele pode-se contemplar conteúdos linguísticos que sejam pertinentes quanto ao seu uso didático. Doravante discutiremos as experiências do ensino da Libras a partir da perspectiva do professor ouvinte e do professor surdo.

\section{O ensino de Libras com professores ouvintes no ensino superior}

O decreto 5.626 viabiliza o ensino de professores ouvintes para o ensino de Libras no capítulo III, a saber:

Art. 7o Nos próximos dez anos, a partir da publicação deste Decreto, caso não haja docente com título de pós-graduação ou de graduação em Libras para o ensino dessa disciplina em cursos de educação superior, ela poderá ser ministrada por profissionais que apresentem pelo menos um dos seguintes perfis:

I - professor de Libras, usuário dessa língua com curso de pósgraduação ou com formação superior e certificado de proficiência em Libras, obtido por meio de exame promovido pelo Ministério da Educação;

I - instrutor de Libras, usuário dessa língua com formação de nível médio e com certificado obtido por meio de exame de proficiência em Libras, promovido pelo Ministério da Educação;

III - professor ouvinte bilíngue: Libras - Língua Portuguesa, com pósgraduação ou formação superior e com certificado obtido por meio de exame de proficiência em Libras, promovido pelo Ministério da Educação. (BRASIL, 2005.)

Como o decreto discorre, trata-se de pessoas com conhecimento da língua comprovado mediante formação ou exame de proficiência. 


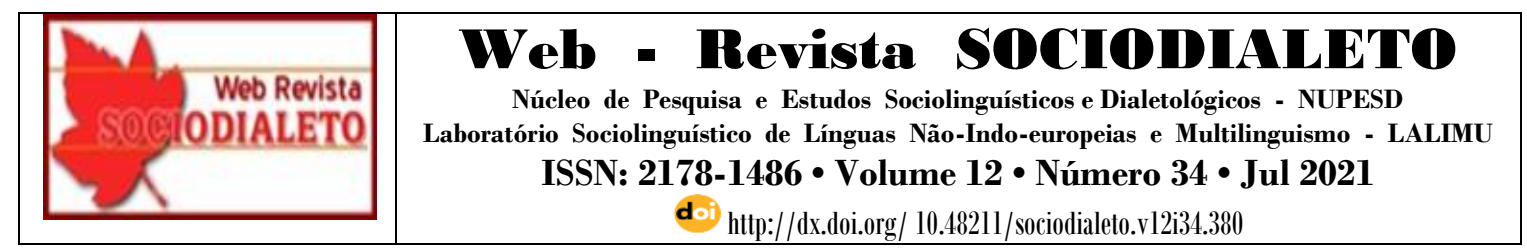

Neste sentido, os professores ouvintes realizam o ensino e apostam em métodos e técnicas que facilitem e contribuam para o melhor aprendizado da disciplina. Esses métodos são variados oscilando entre teoria e prática e muitos estão relacionados com a quantidade de horas que a disciplina contém.

Apesar das diferenças entre as escolhas dos docentes nas opções teoria e prática, somente prática, e iniciando, primeiro, pela prática e depois, teoria, os conteúdos aqui apresentados pelos mesmos tornam-se pouco viáveis de serem apresentados apenas em um semestre. (YATIM; PEREIRA, 2016, p.12)

A padronização do tempo é uma questão muito relevante tanto para a prática de ensino quanto para a aprendizagem. Uma vez que não há uma padronização na carga horária da disciplina não há como demarcar que em todos os cursos os conteúdos vistos foram semelhantes. Isso também interfere nas escolhas didáticas pois alguns temas em Libras requerem didáticas bem singulares para serem explicadas. Para falar de classificadores, por exemplo, não é possível fazer isso apenas com uma aula expositiva e discursiva sobre o assunto. De outra forma, requer uso e exposição prática para a construção de sentido dessa categoria.

Ainda mencionando sobre o quesito da heterogeneidade das turmas, os professores precisam lidar com essa realidade e pensar sobre seus desafios, uma vez que a primeira conclusão que podemos chegar pode ser da impossibilidade de trabalhar em um ambiente dessa forma. No entanto, há que se percorrer o caminho inverso, ou seja, pensar sobre a possibilidade de se conduzir essa turma e buscar estar cada vez mais próximo desses alunos.

[...] Ademais a realidade é que os contextos nunca são homogêneos, e uma prática de ensino situada requer do professor, em primeira instância aproximar-se de seus alunos e conhecê-los. É uma ilusão, por outro lado, acreditar que trabalhar com grupos linguisticamente homogêneos tornaria a empreitada mais fácil para o professor... (GESSER,2012, p. 56) 


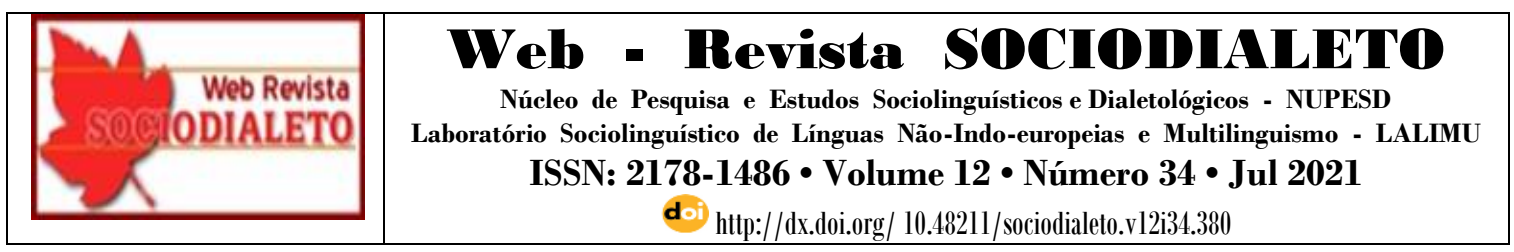

Essa colocação põe em debate as práticas docentes de modo geral. É comum se pensar que quanto mais nivelada a turma estiver e quanto mais próximos e singulares foram os conhecimentos dos alunos, mais fácil se torna para os professores conseguirem atingir com êxito seu trabalho. No entanto, o que temos é justamente o contrário, uma vez que por mais eficaz que seja o nivelamento, existem outras nuances envolvidas no ato de ensinar/aprender.

\section{A experiência no ensino de LIBRAS com professores surdos}

A presença do professor surdo é muito importante no ensino da Libras, pois há a identificação, pois os alunos percebem e se identificam com aquele indivíduo, há uma interação com aqueles conhecimentos e com aquela cultura, o que configura algo relevante pois,

nos processos identificatórios, vários professores surdos apresentam representações da identificação e reconhecimentos do olhar e da cultura surda, porque conhecem a história dos surdos e sabem, através do seu jeito ensinar, levar outros surdos a identificar a própria cultura. Assim, a identificação surda envolve um processo pelo qual um surdo se identifica com o outro, seja pela língua de sinais, cultura, alteridade, diferença do ser, o que é um aspecto central para o sujeito que está atuando. (REIS, 2007, p. 93-94)

Essas vivências, sem dúvida fazem o diferencial no processo de ensinoaprendizagem, então, faz-se importante trilhar em direção à pedagogia surda uma vez que é necessário traçar novos rumos na história da educação dos surdos, e esses rumos devem ser direcionados por seus principais sujeitos. A ruptura com o modelo de educação ouvinte se insere nessa proposta e surge a valorização da identidade e da cultura do surdo feita por e para ele.

A trajetória dos professores surdos, por mais que pareça recente, não é, e na verdade, desde quando se pode falar em educação de surdos já é possível identificar a sua presença neste espaço, se pensarmos os inúmeros e influentes jovens surdos do Instituto 


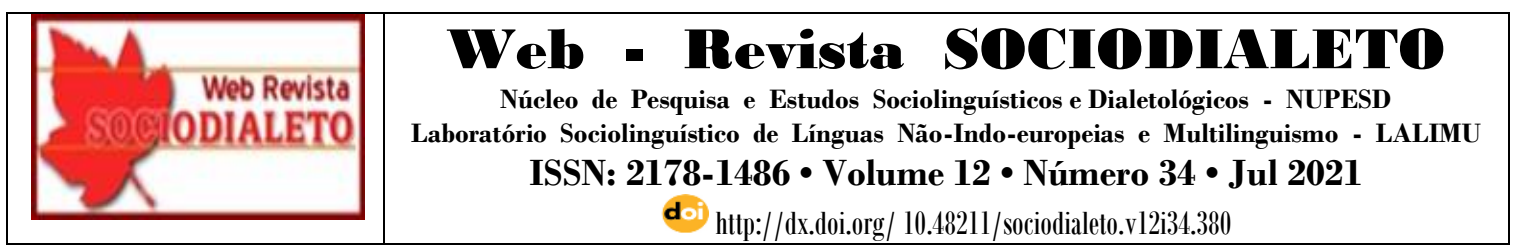

de Paris, como Ernest Huet e Laurent Clerc e entre outros que os antecederam e sucederam também . Isso é importante, pois fortalece a ideia de que eles podem e devem estar à frente do seu processo educativo. Ao longo dos anos fomos vendo o despertar de muitos professores surdos que se tornaram referência no ensino da língua de sinais.

Aqui no Brasil temos como exemplos Gladis Perlin ${ }^{8}$, Karin Strobel $^{9}$, Nelson Pimenta ${ }^{10}$ e muitos outros que foram surgindo ao longo da história e assumindo essa tarefa de conduzir o ensino da cultura surda. Todos eles deixaram suas contribuições em pesquisas sobre a língua e ainda exercem grande influência dentro da área.

Durante a pesquisa bibliográfica, algumas metodologias utilizadas para o ensino de surdos no ensino superior foram levantadas, a saber:

1. Exposição sobre a estruturação linguística, estudo comparativo da gramática da LIBRAS e da Língua Portuguesa, para na sequência possibilitar a estruturação das frases e dos diálogos em LIBRAS quantos as aulas práticas;

2. A interação comunicativa acontece a partir de um tema selecionado antecipadamente de forma sinalizada, envolvendo o conteúdo já explorando;

3. Levantamento do vocabulário a partir de dinâmicas de grupo ou duplas

4. Projeções de documentários de curta duração sobre língua de sinais

5. Dinâmicas envolvendo expressões faciais e corporais

6. Análise e Discussão de texto referente ao conteúdo em destaque

\footnotetext{
8 graduação em Licenciatura em Teologia pela Pontifícia Universidade Católica do Rio Grande do Sul (1987), mestrado (1998) e doutorado em educação pela Universidade Federal do Rio Grande do Sul (2003). Gládis foi a primeira surda a obter o título de doutora no Brasil. Professora da Universidade Federal de Santa Catarina.

${ }^{9}$ Doutora na área de educação na Universidade Federal de Santa Catarina UFSC (bolsista CNPq), formada em pedagogia da UTP (Universidade Tuiuti do Paraná) e com especialização em área de surdez. Autora do livro "As imagens do outro sobre a cultura surda".

${ }^{10}$ Doutorando em Pós-Graduação em Estudos da Tradução pela Universidade Federal de Santa Catarina UFSC, Mestre em Estudos de Tradução e se formou em Literatura-Libras da UFSC e cinema na Universidade Estácio de Sá. Tem certificação PROLIBRAS-MEC-UFSC como professor de nível superior e é autor/coautor de 15 livros em Libras.
} 


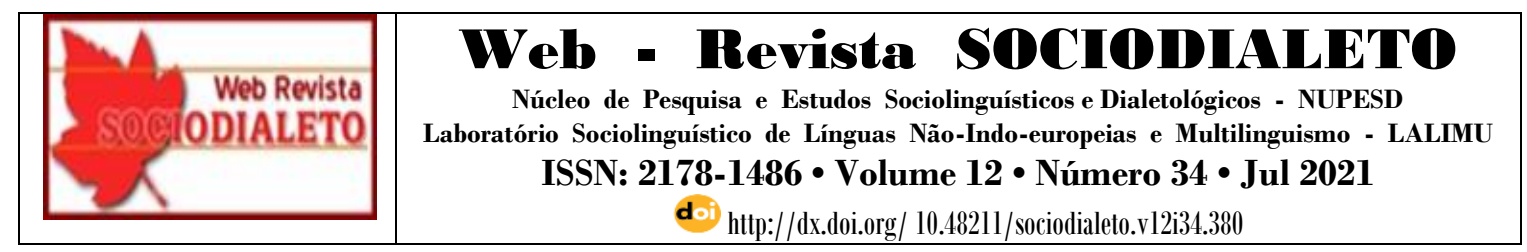

O professor poderá utilizar o quadro branco e outros recursos didáticos, Datashow, computador, filmes legendados e textos referentes ao conteúdo e considerar para fins de avaliação os seguintes critérios: assiduidade; pontualidade; participação produtiva nas atividades propostas (análise e interpretação de texto); avaliação escrita ou visual; aulas em LIBRAS e seminário em grupo.

Assumir um posicionamento dinâmico e diversificado no que tange aos recursos didáticos se torna imprescindível para o sucesso do aluno surdo, pois ao articular o seu saber com sua ação prática é importante para que a aprendizagem se torne significativa, além de interiorizar e avaliar as elaborações teóricas a partir da sua ação (GHEDIN, 2012, p.135). Sobre esse ato reflexivo o autor ainda aponta

\begin{abstract}
A experiência docente é o espaço gerador e produtor de conhecimento, mas isso não é possível sem uma postura sistematização que passa por uma postura crítica do educador sobre as próprias experiências. Refletir sobre os conteúdos trabalhados, as maneiras como se trabalha, a postura frente aos educandos, frente ao sistema social, político, econômico, cultural é fundamental para se chegar à produção de um sabe fundado na experiência. (GHEDIN, 2012, p.135)
\end{abstract}

A postura do professor crítico, reflexivo faz parte de muitas defesas teóricas, posto que se compreende como importante assumir essa posição por entender que existe uma relação dinâmica entre a prática docente e a reflexão que se faz nela e dela e esta deve acontecer antes, durante e após a aula, tornando-se habitual. (GESSER, 2012, p. 25).

Ao observarmos as questões metodológicas e didáticas é possível inferir que os professores se deslocam para o uso de metodologias audiovisuais dentro da abordagem comunicativa apontadas por MARTINEZ (2009) uma vez que existe uma transição entre a execução dos procedimentos metodológicos em questão, não se fixando em apenas uma abordagem. Sobre isso o autor nos aponta que

Estamos falando aqui de uma abordagem mais universalista, na qual não se trata de exercícios baseados em uma descrição contrastiva das 


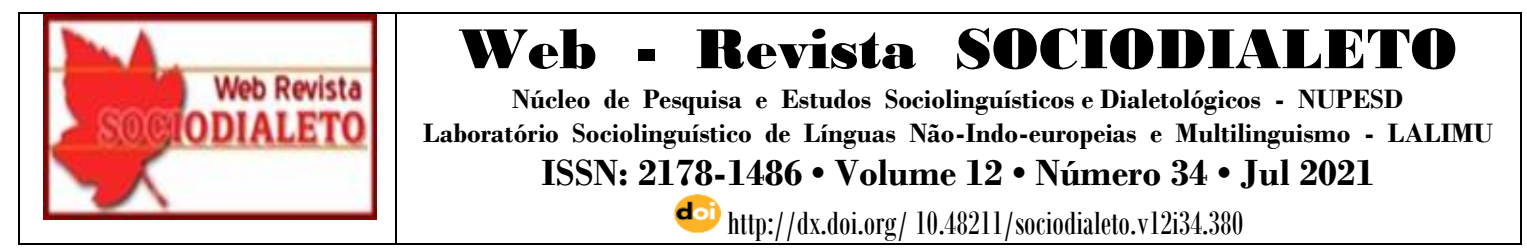

línguas. Mas rapidamente muitos métodos contextualizados, isto é, adaptados a esse ou àquele grupo linguístico, vão se liberar desta restrição. (MARTINEZ, 2009, p. 61)

Pode-se perceber ainda que essas práticas inscrevem a experiência de professores surdos no ensino superior dentro daquilo que MACHADO (2015, p.23) demarca. Desta forma é possível inferir que a experiência de ter um professor surdo é muito significativo para os alunos, pois no ensino está imbricado as experiências e vivências que poderão ser compartilhadas de forma subjetivas com seus alunos (as).

Por fim, nota-se que a sugestão que é apresentada por Gesser (2012) é assimilada e utilizada pelos professores no ensino superior uma vez que ela sugere:

[...] faça uso da linguagem autêntica e contextos significativos, sempre contemplando as necessidades dos alunos. Nos momentos em que abordar os aspectos usuais da língua-alvo ou mesmo nos momentos formais, destaque o papel da interação e da significação, alternando entre técnicas e atividades que foquem a língua não apenas do menor para o maior, isto é, "da parte para o todo (bottom-up), mas especialmente o contrário " do todo para a parte" (top-down). (GESSER, 2012, p. 138)

O ensino de forma contextualizada é crucial para uma aprendizagem significativa sobre qualquer tema e quando o professor consegue fazer uso de suas metodologias dentro desta perspectiva ele adquire elementos muito bons para conseguir atingir os resultados propostos de forma que seus alunos adentrem por meio do aprendizado naquilo que foi ensinado.

\section{Considerações Finais}

Os elementos aqui discutidos apesar de ainda estarem em fase de desenvolvimento, uma vez que a história dos surdos e de suas comunidades continuam sendo tecidas e construídas através de muita luta, muito enfrentamento e sim, muitas 


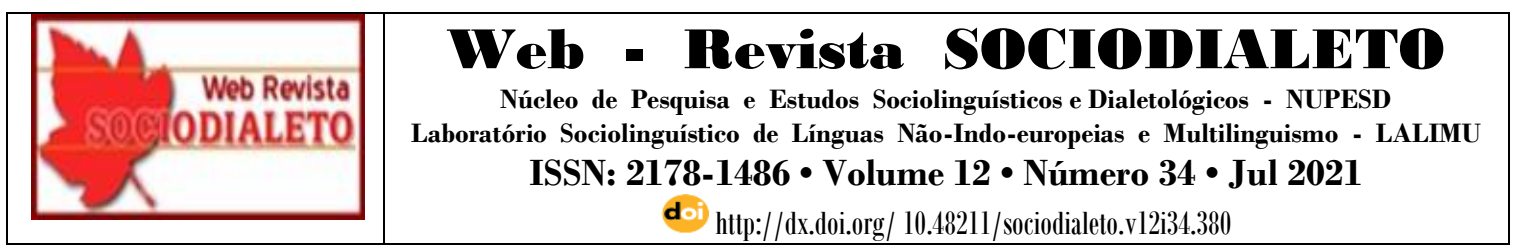

conquistas e principalmente a partir da difusão do conhecimento à respeito da língua de sinais e por sua vez da cultura surda, são capazes de gerar algumas considerações.

É muito gratificante perceber que o processo histórico pelo qual passaram os surdos, apesar de em alguns momentos expressarem certas dificuldades, hoje temos muito que se comemorar e orgulhar, como eles mesmo fazem questão de demonstrar em seus espaços e datas comemorativas, do setembro azul por exemplo.

A garantia e o reconhecimento da língua de sinais, a oficialização da LIBRAS, a educação bilíngue nas escolas e a presença da Libras no ensino superior, ainda que precisem ser mais discutidas e melhor desenvolvidas, configuram um avanço sem igual para o reconhecimento dos modos de vida dessas pessoas.

Hoje, um número maior de pessoas fala sobre eles, conhecem um pouco de sua história, de sua cultura e de sua língua. Alguns vão mais além, outros ficam nas questões básicas. Mas isso é importante para garantir o respeito a essa diferença cultural e social oferecendo condições para uma interação entre esses dois mundos distintos, pois, a educação inclusiva que realmente se deseja é aquela que aborda tanto as identidades surdas quanto as ouvintes que estão em constante interação nos espaços sociais.

O ensino de Libras feito por professores ouvintes ainda é crucial, uma vez que muitos desses docentes estão imersos já há muito tempo dentro das comunidades surdas, compartilhando de suas experiências e contribuindo tanto para a difusão e amplo conhecimento a respeito da língua de sinais quanto pela diminuição da distancia e derrubada dos muros erigidos entre os mundos do surdo e do ouvinte.

Aos professores surdos, que se encarregam da tarefa de ensinar sobre sua identidade, sua língua, sua vida, principalmente para os ouvintes, fato que não expressa nenhuma facilidade devem compreender que esta pode ser a única oportunidade de troca intercultural que pode existir entre eles e outros surdos que podem extrapolar as barreiras da sala de aula para isso podem e devem propiciar um ambiente amigável e pautado pela colaboração entre ambos para uma boa aprendizagem. 


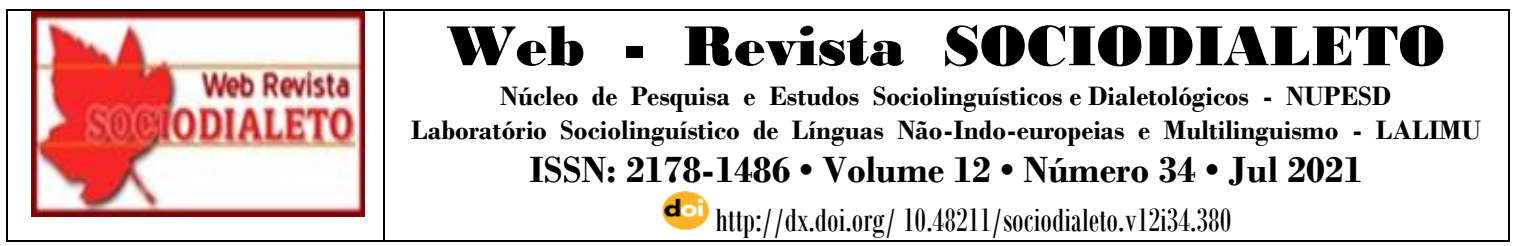

\section{Referências}

BRASIL. Lei 10.436 de 24 de abril DE 2002. Dispõe sobre a Língua Brasileira de Sinais - LIBRAS e dá outras providências. Brasília, DF, 2002.

BRASIL. Decreto ${ }^{\circ} 5.626$ de 22 de dezembro de 2005. Regulamenta a Lei no 10.436, de 24 de abril de 2002, que dispõe sobre a Língua Brasileira de Sinais - Libras, e o art. 18 da Lei no 10.098, de 19 de dezembro de 2000. Brasília, DF, 2005.

DINIZ, Heloíse Gripp. A história da Língua Brasileira de Sinais (LIBRAS): um estudo descritivo das mudanças fonológicas e lexicais. 144f. Dissertação, Universidade Federal de Santa Catarina, Florianópolis, 2010.

FREIRE, Paulo. Educação como prática da liberdade. Rio de Janeio: Paz e Terra. 2009.

GIL, A. C. Como elaborar projetos de pesquisa. 4. ed. São Paulo: Atlas, 2008

GESSER, Audrei. Libras: que língua é essa. São Paulo: Parábola, 2009.

GESSER, Audrei. O ouvinte e a surdez: sobre ensinar e aprender LIBRAS. São Paulo: Parábola Editorial, 2012.

GHEDIN, E. Professor reflexivo: da autonomia da técnica à autonomia da crítica. In: PIMENTA, Selma Garrido; GHEDIN, Evandro (Orgs). Professor reflexivo no Brasil: gênese e crítica de um conceito. São Paulo: Cortez, 2012 (CAP. 6, p. 148-173).

MARCONI, Maria de Andrade; LAKATOS, Eva Maria. Metodologia do trabalho científico. 7. ed. São Paulo: Atlas, 2012

MARTINEZ, Pierre. Didática de Línguas Estrangeiras. Tradução: Marco Marcionílio. São Paulo: Parábola Editorial, 2009.

QUADROS, Ronice Müller de. Educação de Surdos - A aquisição da linguagem. Porto Alegre: Artes Médicas, 1997.

QUADROS, Ronice Müller de; SCHMIEDT, Magali L. P. Idéias para ensinar português para alunos surdos. Brasília: MEC, SEESP, 2006.

REIS, Flaviane. Professor surdo: identificação ou modelo? In: QUADROS, Ronice Müller de; PERLIN, Gladis. Estudos surdos II. Petrópolis, RJ: Arara Azul, 2007, p. 8699.

SANTOS, Emanuelle Félix dos. Tecendo leituras nas pesquisas sobre LIBRAS: sentidos atribuídos ao seu ensino na educação superior. IN: ALMEIDA, Wolnei Gomes. Educação de surdos: formação estratégias e práticas. Ilhéus - BA: Editus, 2015.

STROBEL, Karin Lilian. História dos surdos: representações "mascaradas" das identidades surdas. In: QUADROS, Ronice Müller de; PERLIN, Gladis (orgs). Estudos Surdos II. Petrópolis, RJ: Arara Azul, 2007. p. 18-37.

STROBEL, Karin Lilian. História da educação de surdos (apostila da disciplina do curso de Letras Libras - UFSC). Florianópolis: Universidade Federal de Santa Catarina UFSC, 2009. 


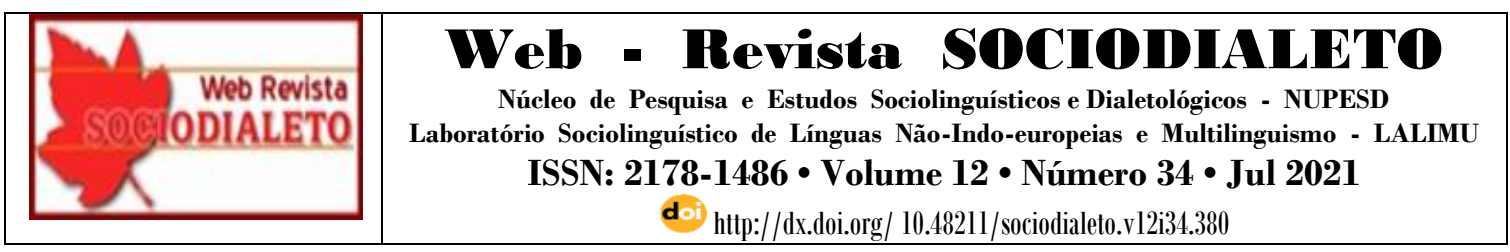

STUMPF, Mariane Rossi. Educação bilíngue para surdos: relatos de experiências e realidades brasileiras. In: QUADROS, Ronice Müller, de; STUMPF, Mariane Rossi (orgs). Estudos Surdos IV, Petrópolis, RJ: Arara Azul, 2009. P. 425-50.

WILCOX, Sherman; WILCOX, Phillis Perrin. Aprender a ver: O ensino de língua de sinais americana como segunda língua. Tradução: Tarcísio de Arantes Leite. Editora Arara Azul. 2005.

YATIM, Nahla; PEREIRA, Janaí de Abreu. Aprendizagem de LIBRAS com L2 no ensino superior. Revista Virtual de Cultura Surda, edição 18, jul 2016.

Recebido em: 19/02/2021 | Aprovado em: 25/05/2021. 